\title{
Differences in Parameters of an Embryo In Vitro Production Program between Cattle (Bos Indicus) and Buffaloes (Bubalus bubalis)
}

\author{
Jesús Alfredo Berdugo ${ }^{1, *}$, Ariel Marcel Tarazona-Morales ${ }^{2}$, José Julian Echevererry ${ }^{1}$, \\ Jose Luis Konrad ${ }^{3}$, Gustavo Angel Crudeli ${ }^{3}$ and Albeiro Lopéz-Herrera ${ }^{1}$
}

\author{
${ }^{1}$ BIOGEM, Facultad de Ciencias Agrarias, Universidad Nacional de Colombia, Sede Medellín, Carrera 65 No \\ 59a 110. BI 50 of 231 Medellín, Colombia \\ ${ }^{2}$ BIOGENESIS, Facultad de Ciencias Agrarias, Universidad Nacional de Colombia, Sede Medellín, Carrera \\ 65 No 59a 110. BI 50 of 231 Medellín, Colombia \\ ${ }^{3}$ IBRA, Catedra de Teriogenologia, Facultad de Ciencias Veterinarias, Universidad Nacional del Nordeste, \\ Corrientes, Argentina Sargento Cabral 2139 (3400) Corrientes Capital, Argentina
}

\begin{abstract}
In order to improve production, it is necessary to apply reproductive biotechnologies, including embryo transfer. Due to the management and physiology of the animals and the buffalo production system, the best system is the in vitro production of embryos (IVP). This work aims to compare the results of the (IVP) of cows (Bos indicus) and buffalo (Bubalus bubalis) from animals kept under the same conditions of feeding and handling. This study was conducted in an Argentinan commercial herd located in the province of Corrientes (-27.742859 latitude, -57.773611 longitude) that raise buffaloes and cattle, during the breeding season of 2018 (March-May). Twenty animals of each species were used. Antimullerian hormone (AMH) levels of each animal were determined using ELISA. Standardized protocols were used for oocyte aspiration, maturation, fertilization and culture of the embryos, frozen semen of a single proved bull was used in each species. Information about the number of follicles, oocytes, and embryos was recorded and analyzed individually and grouped by species. The normality of the data was evaluated with the D'Agostino and Shapiro-Wilk tests and the comparisons between species using the Mann Whitney and ANOVA tests. Values are shown as median and range. A p-value $<0.05$ was considered statistically significant. The AMH levels of the cows were 688.5 $\mathrm{pg} / \mathrm{ml}$ (45.3-2394) and the buffaloes $73.8 \mathrm{pg} / \mathrm{ml}(14.8-262.5), \mathrm{p}<0.001$. Significant differences were found in the number of recovered oocytes $9(0-23)$ cows vs. $4.5(1-11)$ buffaloes $(p>0.05)$. There were no significant differences in the number of follicles and the quality of the oocytes. Significant differences were found in the number of oocytes cleaved 4 $(0-17)$ vs. $0.5(0-4)$ and blastocysts/animal $1,5(0-15)$ and $0,1(0-2)$ I for cows and buffalos respectively. The number of blastocysts in relation to the number of oocytes cleaved did not show statistical significance. The differences in the levels of $\mathrm{AMH}$ and the marked differences in the IVP between buffaloes and cattle are confirmed, it is necessary to propose research proposals that explain the differences.
\end{abstract}

Keywords: IVPE, buffaloes, AMH, Differences.

\section{INTRODUCTION}

Exists a worldwide interest in buffalo production due to the advantages of producing meat, milk, and work, using more deficient forages in tough environmental conditions such as heat, lack of water, parasites and tropical diseases, especially in tropical and subtropical zones of the world, compared to cattle. It has been reported an increase in the world buffalo population from 1961 to 2013 in $125 \%$, according to FAO [1]. As a growing industry need the generation and adoption of genetic improvement programs that make it a more profitable production system, one option is using assisted reproductive technologies (ART), such as embryo transfer. Our expanding knowledge of ovarian function during the oestrous buffalo cycle has

*Address correspondence to this author at the BIOGEM, Facultad de Ciencias Agrarias, Universidad Nacional de Colombia, Sede Medellín, Carrera 65 No 59a 110. BI 50 of 231 Medellín, Colombia; Tel: 57 5898335;

E-mail: jaberdugog@unal.edu.co given new approaches for the precise synchronization of follicular development and ovulation to be applied consistently to embryo production, especially in vitro (IVP).

It is well known that buffalo and cattle have similarities in the reproductive patterns, the same gonadotropins and sexual steroids direct it. $63.3 \%$ of buffaloes shows two follicular waves cycle [2], follicle deviation occurs 2.6 days after ovulation when the diameters of the dominant and subordinate follicle are 7.2 and $6.4 \mathrm{~mm}$, respectively, in general, similar luteal phase and oestrous cycle length [3].

The number of primordial cells in buffalo ovaries is about 10-fold lower than in cattle [4], and also the number of antral follicles [5]. There are differences associated with total follicle count and follicles recruited per follicular wave, and it is lower in buffalo than cattle [6]. Furthermore, it was verified that 92 to $95 \%$ of follicles are estrogen inactive/atretic at random stages 
of the reproductive cycle. The outcome of the ovary morphogenesis during fetal life ultimately leads to the neonatal ovary to contains primordial follicles, the functional unit of the ovary. These follicles will be responsible for the development of healthy and fertilizable oocytes as well as the production of female hormones in adulthood. Recently it has been demonstrated the effectiveness of dosage of antimullerian hormone (AMH), as a marker of the follicular population of the females (ovarian reserve) [7]. The major factors limiting the commercial use of IVEP in buffaloes are: the low number of oocytes recovered; their low cleavage rate; and the poor success of cryopreservation of IVEP buffalo embryos [8], low freezability of IVEP buffalo embryos associated with high lipid content [9]. It has been demonstrated that enriching the IVM medium with thiol compounds, such as cysteamine and cysteine, improves IVEP efficiency in buffalo by stimulating oocyte GSH synthesis [10].

Other difference between cattle and buffaloes is the scarcity of the results of in vivo embryo recovery in superovulated buffaloes. As a consequence, the association of oocyte pick up (OPU) and in vitro embryo production (IVEP) represents an alternative method of exploiting and multiplying genetics of superior merit females [11], it has been reported lower outcomes in buffalo $[12,13]$ than cattle embryos [14]. Recently researchers have been demonstrated the potentialities of the commercial use of IVP in buffalo species. Few information is related to compare IVP of the two species as a way to identify factors that could be useful in improving results, moreover, to learn different aspects of reproductive biology. In order to find clues that allow researchers to find explanations of the observed events, this paper aims to compare the performance of cattle (Bos indicus) and buffaloes (Bubalus bubalis) in an in vitro embryo production program.

\section{METHODS AND MATERIALS}

\subsection{Animals}

The current work was performed in an Argentinan buffalo herd, located in the province of Corrientes (-27.742859 latitude, -57.773611 longitude), during the breeding season of 2018 (March-May). All procedures were reviewed and approved by the Animal Welfare Committee, (Universidad Nacional del Nordeste, Corrientes, Argentina), and conducted according to ethical standards of the Institution.
For this study 40 animals were used, 20 buffaloes (crossbred Murrah and Mediterranean) and 20 cows of the Brangus breed of 3 to 5 years of age, without abnormalities in their external genitalia, of proven fertility with a body condition score of $3.48 \pm 0.11$ ( 1 to 5 scale), grazing on Brachiaria decumbens and minerals ad libitum. All experimental animals were considered to be cyclic based on ultrasound detection of corpus luteum before initiation of treatments and consistent ovarian activity with the presence of multiple follicles per ovary (Pie Medical S100 ultrasound (Maastricht, Netherlands) with a sectorial probe (5.0 to $7.5 \mathrm{MHz}$ ). Cattle and buffaloes were summited to the same procedures.

\subsection{Oocyte Obtention (OPU)}

To facilitate the manipulation of animals for the follicular aspiration, 2\% Xylazine was used at $0.25 \mathrm{ml} / 100 \mathrm{~kg}$ doses. And at the moment of aspiration 5 to $7 \mathrm{ml}$ of Procaine (Procasel) epidurally were administrated. Follicular aspiration was performed according to the reported by Konrad et al., 2017 [15]. Briefly, oocytes were obtained by aspiration small-sized follicles (3 to $7 \mathrm{~mm}$ ), using ultrasonography (Mindray DP-30 Vet), with a $5 \mathrm{MHz}$ transvaginal probe, attached to a $60 \mathrm{~cm}$ device adapted for the aspiration and conduction of follicular fluid (WTA, Brazil). Once the follicles were visualized in the ovary, they were aspirated with a $17 \mathrm{G}$ gauge needle, with a vacuum pressure of $40-60 \mathrm{mmHg}$. The obtained follicular fluid was collected in 50-ml polypropylene conical tubes (Corning ${ }^{\circledR}$ Life Sciences, MA, USA), containing $1 \mathrm{ml}$ of a buffered saline solution (DPBS, Serendipia Labs, Argentina), supplemented with 100 units USP / ml of heparin, and $1 \% \vee / \vee$ of fetal bovine serum (SBF, Natocor, Argentina), and penicillin-streptomycin and maintained at $37^{\circ} \mathrm{C}$. After each aspiration, the line was washed with the same buffered saline solution.

To obtain the oocytes, the aspirated follicular fluid was passed through a 75 um filter (WTA, Brazil), and the filtrated aspirated follicular fluid was transferred to a Petri dish filled with DPBS. After decantation, the oocytes were identified using a stereomicroscope with $50 \mathrm{X}$ magnitude over a preheated work station at $37^{\circ} \mathrm{C}$.

\subsection{Classification and Culture of Oocytes}

Cumulus-oocyte complex quality was classified based on the number of layers of compact cumulus cells and the presence of homogenous cytoplasm from I to IV (I- highest to IV- poorest) [16]. Once classified, 
COCs were washed and transferred to a $35-\mathrm{mm}$ Petri dish containing $3 \mathrm{ml}$ of maturation medium, consisting of TCM 199 with Earl's salts and 25 mM HEPES, 10\% $\mathrm{v} / \mathrm{v}$ FBS, $50 \mathrm{mM}$ cysteamine, $5 \mu \mathrm{g} / \mathrm{ml} \mathrm{FSH} \mathrm{(NIH-FSH}-$ P1; Folltropin-V; Bioniche Animal Health, Belleville, Ontario, Canada) and $0.1 \% \mathrm{v} / \mathrm{v}$ gentamycin sulfate (Gibco, Thermo Fisher Scientific, gentamicin reagent solution, $50 \mathrm{mg} / \mathrm{ml}$ ). They were then transferred to 1.8 $\mathrm{ml}$ Eppendorf tubes filled with pre-equilibrated maturation medium and transported to the IVF laboratory ( $8 \mathrm{~h}$ from the farm) in a portable incubator (Minitube, Germany) set at $37^{\circ} \mathrm{C}$.

\section{In Vitro Fertilization}

At the laboratory, groups of 10 oocytes were transferred to $50 \mathrm{ul}$ drops of maturation medium under mineral oil. After 15 - 18 hours of maturation [17], oocytes were removed from the maturation medium, washed three times and placed in the insemination medium [18]. All inseminations were conducted using straws from one single buffalo or cattle bull of proven fertility and good in vitro performance.

Semen for fertilization was prepared by the swim-up technique. Straws were thawed at $37.5^{\circ} \mathrm{C}$ for one minute, diluted with fertilization medium and centrifuged for 5 minutes at $400 \mathrm{~g}$. The supernatant was removed, and the pellet was resuspended and placed in a conical tube with $1 \mathrm{~mL}$ of the new medium for 45 minutes at $38.5 \mathrm{C}$ in an atmosphere of $5 \% \mathrm{CO} 2$, after migration the supernatant was transferred to a conical tube, the motility and concentration were determined. Oocytes were inseminated in $50 \mathrm{ul}$ drops with a concentration of $1 \mathrm{million} / \mathrm{spermatozoa} / \mathrm{ml}$. The oocytes were left with sperm at $38.5 \mathrm{C}$ and $5 \% \mathrm{CO} 2$ for 16 hours and the presumptive zygotes were transferred to the embryo culture medium in 50ul SOFaa-BSA drops supplemented with $5 \% \mathrm{v} / \mathrm{v}$ SBF. $0.3 \% \mathrm{w} / \mathrm{v}$ bovine serum albumin free. Remaining cumulus cells were removed by repeated pipetting in TCM 199 medium with Hank's salts supplemented with $0.1 \%$ w / v hyaluronidase $(400-1000$ units $/ \mathrm{mg})$. Finally, the presumptive zygotes were cultured $(5 \mu \mathrm{ll}$ culture medium / presumptive zygote) under $5 \% \mathrm{CO} 2,5 \% \mathrm{O} 2$ and $90 \% \mathrm{~N} 2$ at $38.5 \mathrm{C}$ in SOFaa-BSA medium [19], with $0.3 \% \mathrm{w} / \mathrm{v}$ fatty-acid free BSA for the first 3 days of culture. The medium was changed on day 4 of culture. The cleavage rate was recorded, and the medium was changed to SOFaa-BSA with the addition of $5 \% \mathrm{v} / \mathrm{v}$ FBS. At day seven all blastocysts obtained were recorded.

\subsection{Antimullerian Hormone Determinations}

At the moment of animal selection, blood samples were taken in an anticoagulated tube (EDTA, Vacutainer, Beckton Dickinson) with a 21 gauge needle for cattle and 18 gauge needle from the jugular vein. Serum was aliquoted and frozen at $-20^{\circ} \mathrm{C}$ until $\mathrm{AMH}$ determinations using a commercial AMH ELISA kit (Cat

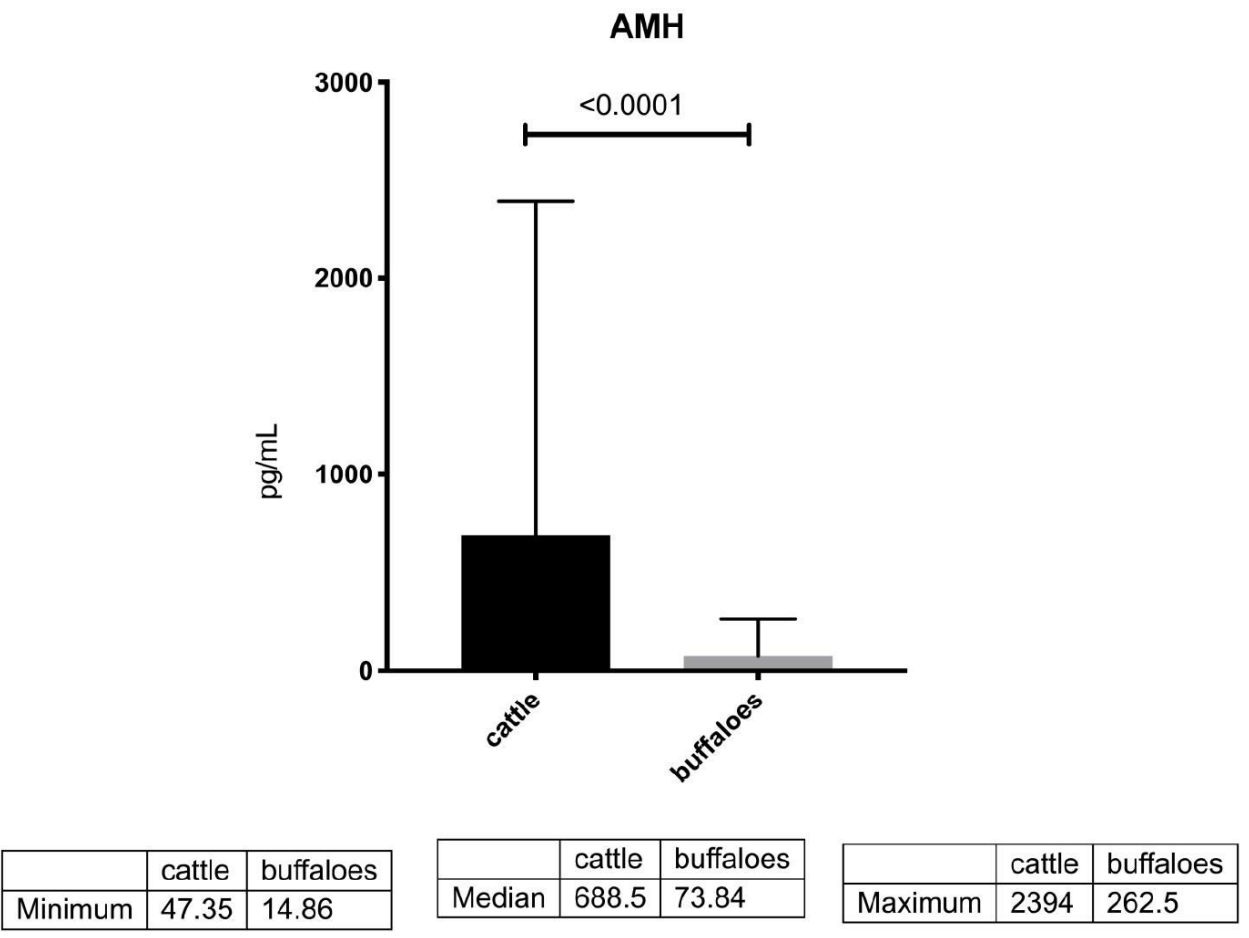

Figure 1: Differences in AMH levels between cattle and buffaloes. 


\section{Cattle and Buffaloes}

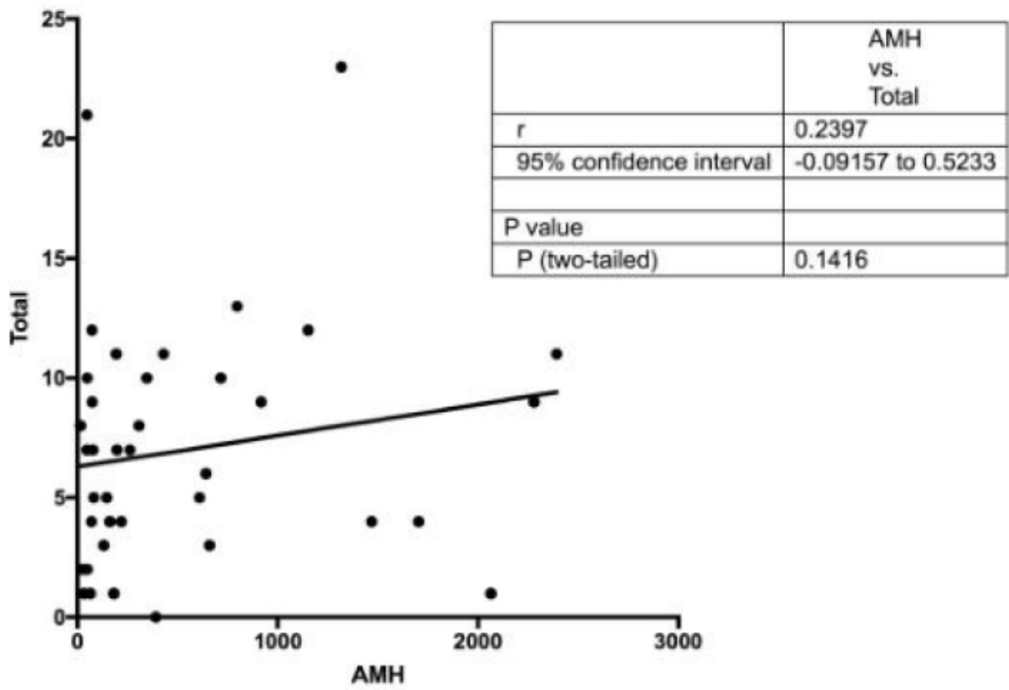

Figure 2: Correlation analysis of $\mathrm{AMH}$ values and total follicle number of buffaloes and cattle.

No AL-114 Lot No 010616-B Ansh Labs, Webster, TX, USA) following the instructions of the manufacturer.

\subsection{Statistical Analysis}

The normality of the data was determined using D'Agostino and Shapiro-Wilk tests. All values of each variable are expressed as median and the range. Comparisons were performed using the Mann Whitney test. Continuous data were analyzed by analysis of variance (ANOVA) using a repeated measures model, and proportional data were analyzed by Chi-square test using GraphPad Prism v.7 software. Differences were considered statistically significant at $p<0.05$.

\section{RESULTS}

For the analysis, 20 cattle and 19 buffaloes were included, $\mathrm{AMH}$ levels, right, left and total follicle number, number and quality of oocytes and the number of viable oocytes, cleaved and blastocysts were

Table 1: Comparison of Individual Values of AMH Levels, Oocyte Quality and Embryo Production between Cattle and Buffaloes

\begin{tabular}{|c|c|c|c|}
\hline Parameter & $\begin{array}{c}\text { Cattle } \\
\text { median(range) }\end{array}$ & $\begin{array}{c}\text { Buffaloes } \\
\text { median(range) }\end{array}$ & $p$ value \\
\hline AMH (pg/ml) & 688.5(45.3-2394) & $73.8(14.8-262.5)$ & $p<0.001$ \\
\hline \multicolumn{4}{|l|}{ Follicles } \\
\hline Follicles right ovary & $3(0-9)$ & $4(0-6)$ & \\
\hline Follicles left ovary & $5(0-10)$ & $4(1-8)$ & \\
\hline Total follicles & $7(2-18)$ & $7(2-12)$ & \\
\hline \multicolumn{4}{|l|}{ Oocyte quality } \\
\hline $\mathrm{Gi}$ & $2(1-3)$ & $1.5(1-3)$ & 0.2281 \\
\hline GII & $2(1-9)$ & $2(1-6)$ & 0.6701 \\
\hline GIII & $2.5(0-18)$ & $2(1-4)$ & 0.9101 \\
\hline GIV & $1(1-5)$ & $2(1-4)$ & 0.1007 \\
\hline Total oocytes & $9(0-23)$ & $4.5(1-11)$ & 0.0241 \\
\hline Total viable & $5.5(0-21)$ & $5(0-11)$ & 0.3667 \\
\hline Cleavage & $4(0-17)$ & $0.5(0-4)$ & 0.0009 \\
\hline Blastocyst & $1.5(0-15)$ & $0.1(0-2)$ & 0.0255 \\
\hline
\end{tabular}


Table 2: Comparison of In vitro Embryo Production Parameters between Cattle and Buffaloes

\begin{tabular}{|c|c|c|c|}
\hline \multicolumn{4}{|c|}{ Comparison of IVP parameters between cattle and buffaloes (absolute numbers) } \\
\hline Parameter & Cattle & Buffalo & p-Value \\
\hline Total oocytes & 174 & 96 & 0.0004 \\
\hline Viable oocytes & 145 & 91 & 0.0015 \\
\hline Cleavage & 89 & 17 & $<0.0001$ \\
\hline Blastocysts number & 51 & 8 & $<0.0001$ \\
\hline \multicolumn{4}{|l|}{ Significant difference $p>0.05$. } \\
\hline \multicolumn{4}{|c|}{ Comparison of IVP parameters between cattle and buffaloes (percentage) } \\
\hline Parameter & Cattle & Buffalo & p-Value \\
\hline$\%$ viable oocytes & 83.33 & 94.79 & 0.356 \\
\hline$\%$ cleavage from total oocytes & 51.17 & 17.7 & $<0.001$ \\
\hline$\%$ cleavage from viable oocytes & 61.37 & 18.68 & $<0.001$ \\
\hline$\%$ Blastocyst/ Total & 29.31 & 8.33 & 0.0275 \\
\hline$\%$ Blastocyt/ Viable & 35.12 & 8.79 & 0.0298 \\
\hline$\%$ Blastocyst/Cleavage & 57.3 & 47.05 & 0.7831 \\
\hline
\end{tabular}

determined, as shown in Tables 1 and 2. Only one animal doesn't produce oocytes in each group. The maximum number of oocytes was 11 and 23 for buffaloes and cattle, respectively.

\section{DISCUSSION}

This report is one of the few in the literature that compares in the production of buffalo and cattle embryos with animals raised in the same farm conditions to avoid discussions related to environmental and management factors that affect reproduction $[9,19,20]$. Embryo production is a need for developing a buffalo industry. To date, under the normal management of herds, it is easiest to identify superior females than males. As mentioned before the low results obtained using multiple ovulation and embryo transfer make IVP mandatory for buffaloes. It is a growing production system, very important for the economy of most South American countries, a region that accounts for $23.0 \%$ of the world cattle population. Argentina and Brazil have the largest cattle herds $51,646,544$ and $212,366,132$ heads in 2014 , and embryo production is the most active embryo industries in South America [21]. They were consistently ranked among the top countries doing ET in the past 20 years, and it makes an opportunity to apply the knowledge to buffalo based on the differences observed and gained experience.

\subsection{AMH}

In this work, cattle show higher levels of $\mathrm{AMH}$ compared with buffaloes, $927.17 \mathrm{pg} / \mathrm{ml}$ vs. 100.11 $\mathrm{pg} / \mathrm{ml}$, respectively $(\mathrm{p}<0.0001)$. The results obtained here agree with other researchers [20] regarding the differences in AMH levels between cattle and buffaloes with comparable circulating levels. Due to the high variation in cows 47 to $2279 \mathrm{pg} / \mathrm{mL}$ and buffaloes 32 $262 \mathrm{pg} / \mathrm{ml}$, to date, there are no reports regarding reference values that could be used as parameters for selection, such as humans [22]. Hirayama et al., 2017, report plasma AMH concentrations in Japanese Black cows ranged from 0.032 to $1.992 \mathrm{ng} / \mathrm{mL}$ [23], Ghanem et al., 2016 report plasma AMH concentration in 19 donor cows ranging from 0.08 to $0.84 \mathrm{ng} / \mathrm{mL}$ [24]. In this work the association between $\mathrm{AMH}$ levels and the number of follicles exist a positive relationship $r=02393, p=0.1416$, different to the reported by others $r=0-62 p<0.001[20]$.

$\mathrm{AMH}$ is produced by granulosa cells, and the patterns of expression of $\mathrm{AMH}$ and its type II receptor in the postnatal ovary, indicate that AMH may play an essential role in ovarian folliculogenesis in two critical selection points of follicle development. It inhibits the recruitment of primordial follicles into the pool of growing follicles and also decreases the responsiveness of growing follicles to FSH [25]. It could be possible that the low levels of AMH could affect the responsiveness of follicle to gonadotropins to increase 
the number of follicles, it is paradoxical low levels of $\mathrm{AMH}$ low number of follicles.

The ovarian reserve contains all of the oocytes/primordial follicles potentially available for fertilization throughout the fertile lifespan; each animal has its own, embryo industry needs animals with a more significant ovarian reserve. When OPU is performed, the aim is the aspiration of all identifiable follicles, trying to obtain the maximum number of highquality oocytes for embryo production. In this case, buffaloes and cattle show not statistically different numbers of follicles (7.96 vs. 8.77 follicles/animal), Gimenez et al. [26], report 19.4 and 18.77 for Brangus and buffaloes respectively, that it is numerically higher than reported here, but again it is not statistically significant. It is lower than other reports Baldrighi observed that buffaloes, Holsteins and Gyr cattle have $25,35.9$ and 60 antral follicles respectively at the beginning of the cycle [20]. The follicular population is a reflection of different aspects, including management, genetic background, and environmental factors, buffalo shows low follicle count compared with other bovines and it affects the embryo production programs.

It has been reported differences in hormone levels between species associated with different reproductive parameters, differences in follicle number between Bos indicus and Bos taurus is associated with increasing levels of IGF-I and low FSH concentrations [27], additionally IGF systems express in oocytes and affect in vitro maturation and developmental competence [28], no papers regarding comparison of hormone levels with buffaloes are reported.

In this report, a high recovery rate of $97.7 \%$ and $65.30 \%$ is similar to the obtained for others $79.0 \%$ vs. 72.3 for cattle and buffaloes respectively [19] and $69 \%$ for buffaloes [29]. No comparable reports regarding the technical aspects of the follicular aspiration between cattle and buffaloes were found.

The number of buffalo oocyte is lower than cattle (4.9/al vs. 8.8/al), and it is statistically different $(p=$ 0.0241 ); these results are better than Gasparrini et al., that found 5.3 follicles and 2.7 oocytes/animal. High variability of the number of oocytes recovered has been reported by others and could be explained by the variability in $\mathrm{AMH}$ levels. The number of cattle oocytes recovered is lower than reported by others [30]. Neglia et al. [9] inform that $45 \%$ of their OPU oocytes are grade I or II, results that are similar than those reported here, in the same paper, buffalo oocyte quality is compared with cattle oocytes derived from slaughterhouse and inform that $80 \%$ of oocytes from cattle were of grade I and II compared to $55 \%$ of buffalo. Ferraz et al. obtained 7.6 oocytes/buffalo, and $15.7 \%$ of them were grade IV [29]. The oocyte quality may be affected by several factors, such as the aspiration pressure during collection, the source of gametes, the time between collection and processing, the temperature during transportation, season, etc. In this work, we do not find differences in the quality of the oocytes of the species studies, that it is different than reported by others that inform the worse morphological appearance of buffalo oocytes [9]. Since the morphological evaluation of oocytes is associated with the appearance of an oocyte and granulosa cells, it has been reported differences between oocytes and granulosa cells morphological aspects of buffalo and cattle [31].

\subsection{Embryo Production}

As expected the number of viable oocytes is statistically different between cattle and buffaloes ( $p=$ 0.0262 ). Derived from the problems in grading more buffalo oocytes were classified viable compared with cattle $94.7 \%$ vs. $83.3 \%(p=0.356)$, almost all oocytes were cultured, the results obtained in cattle are not different than others [26]. Baruselli et al., inform in buffalo oocytes lower viability rate of $50 \%$ [32]. Despite that viability could be a subjective parameter, the effect of over cleavage rate and blastocyst rate is important, especially in this paper that it contributes to the lower parameters obtained here.

Cleavage rate and blastocyst are statistically different between buffaloes and cattle $(p<0.001)$, this results are similar to the reported by others, but the numbers are lower, Neglia's report [9] cleavage rate of $83.4 \%$ for cattle and $64.8 \%$ for buffaloes and cattle produce $49.2 \%$ more blastocyst, Gimenes [19] twelve years later found similar results $82.6 \%$ and $63.3 \%$ and $27.3 \%$ more embryos compared to $61.3 \%$ and 18.38 $\%$ and $28.4 \%$ and 27 respectively. This result clearly shows the need for understanding the biology of the buffalo oocyte and embryo.

Cleavage rate reported herein buffalo species are low, suggesting the need to reevaluate the fertilization protocol, because it is undoubtedly poor, despite that blastocyst rate from cleaving embryos are not different between cattle and buffaloes $57.3 \%$ vs. 47.5 ( $p=$ 0.7831 ), this results are higher compared to other $34.1 \%$ and $13.7 \%$ respectively that it is statistically 
different $(p=0.02)$ [19]. The chronology of the development of the embryos is different, and there is evidence from in vivo [33] and in vitro [34] studies that buffalo embryos are morphologically advanced by between 12 and 24 hours compared with cattle embryos.

Protocols for embryo production in buffaloes has been applied from cattle, many efforts have been developed to improve buffalo embryo production, especially by adding molecules such as antioxidants to the culture medium mentioned in the introduction of the paper, the use of IGF-I has been used to improve oocyte maturation and blastocysts cell number [35], Epidermal Growth and higher concentrations of glucose $(5.6 \mathrm{mM})$ [36] factor for blastocyst yield [37], recent studies show that the addition to the medium of leukaemia inhibitory factor [38], hyaluronidase at the end of the culture [39] and L-carnitine facilitates the use of lipid stores [40], improving blastocyst yield, quality and freezability. All these differences clearly show that buffalo oocyte and embryos are physiologically different than cattle, this in part, may explain the low amount of research and consequently, the papers comparing these two species, but it reinforces the new point of view to study reproductive biology, the comparison.

Another strategy to improve buffalo embryo yield is the use of FSH stimulation before ovum pick up, it has been suggested in cattle since 2002 [41] in cattle, some groups have been reported $75 \%$ or more blastocyst rate with the use of coasting protocols [42], and recently it has been declared the improvement in oocyte quality [43] and the number of medium follicles and buffalo embryos, buffalo species [44]. Experiments performed from our group in Colombia and Argentina using $\mathrm{FSH}$ in buffaloes show that $\mathrm{FSH}$ produces more medium-sized follicles $>8 \mathrm{~mm} p=0.0476$, other oocyte numbers, quality, cleavage and blastocyst rates are better than controls but are not statistically different (unpublished data), promising data using $\mathrm{FSH}$ to produce embryos in vitro coming from the use of prepuberal animals is now coming [32]. Paradoxical effects have been reported with the use of bovine somatotropin for in vitro production because despite obtaining statistically different an increase in the number of follicles don't get a reduced proportion of blastocysts per OPU [29].

\subsection{Embryo and Clinics}

It is known that the final pregnancy outcome is in part due to the quality of the embryo, determined by gamete and embryo viability, culture conditions, and in part to the status of the recipient and the perfect embryo-recipient synchrony, in the case of buffalo it has been reported higher embryonic loss than cattle [45], but recent research has been proposed that embryonic loss is associated with concentrations of progesterone (P4) in circulation [46]. In buffalo, however, a strict selection of superior quality embryos would further limit the number of embryos, affecting the benefit-cost ratio. Therefore, as the embryo quality is in part due to the oocyte quality but is also affected by the culture conditions, the optimization of the culture system is still required. In this paper, clinical aspects that also affect the success of an embryo program such as embryo transfer, synchronization of the recipients, season, and clinical conditions of the animals are not considered.

\section{CONCLUSIONS}

Once buffalo embryo production reaches economic parameters, it could be possible to apply all the possibilities of reproductive biotechnology. It is evident that the major intrinsic limitation for the diffusion of IVEP in the field of buffalo is the low number of oocytes recovered per animal. Arising from physiological features of the species such as the low number of primordial and antral follicles, as well as the high incidence of follicular atresia. More research is needed to establish if low $\mathrm{AMH}$ levels are consequence or cause of the low number of primordial follicles are birth in buffaloes and its potential effects over oocyte quality, and obviously improve culture conditios to increase blastocyst rates. A comparison between species could be another approach to study reproductive biology within species.

\section{DECLARATIONS OF INTEREST}

None.

\section{CONTRIBUTORS}

All authors must have materially participated in the research and/or article preparation.

\section{ACKNOWLEDGEMENTS}

The Universidad Nacional de Colombia, Sede Medellín, for the financial support for the Project: Identificación de Polimorfismos en Genes Asociados a la Reserva Ovárica y Proteómica de Oocitos en Vacunos Y Búfalinos", código HERMES 39456 and the Asociación Colombiana de Criadores de Búfalo and 
Asociacion Universitaria Iberoamericana de Posgrado for the financial support for the Student.

\section{REFERENCES}

[1] Food and Agriculture Organization of the United Nations. The state of world fisheries and aquaculture 2016.

[2] Baruselli PS, Mucciolo RG, Visintin JA, Viana WG, Arruda $\mathrm{RP}$, Madureira EH, et al. Ovarian follicular dynamics during the estrous cycle in buffalo. Theriogenology 1997; 47: 1531-47. https://doi.org/10.1016/S0093-691X(97)00159-3

[3] Gimenes LU, Carvalho NAT, Sá Filho MF, Vannucci FS, Torres-Júnior JRS, Ayres $\mathrm{H}$, et al. Ultrasonographic and endocrine aspects of follicle deviation, and acquisition of ovulatory capacity in buffalo (Bubalus bubalis) heifers. Anim Reprod Sci 2011; 123: 175-9.

https://doi.org/10.1016/j.anireprosci.2010.12.004

[4] Manik RS, Palta P, Singla SK, Sharma V. Folliculogenesis in buffalo (<emph type="2">Bubalus $<$ /emph $>\quad<$ emph type="2"> bubalis</emph>): a review. Reprod Fertil Dev 2002; 14: 315-25.

https://doi.org/10.1071/RD01126

[5] Van Ty L, Chupin D, Driancourt MA. Ovarian follicular populations in buffaloes and cows. Anim Reprod Sci 1989; 19: 171-8. https://doi.org/10.1016/0378-4320(89)90090-0

[6] Campanile G, Baruselli PS, Neglia G, Vecchio D, Gasparrini B, Gimenes LU, et al. Ovarian function in the buffalo and implications for embryo development and assisted reproduction. Anim Reprod Sci 2010.

https://doi.org/10.1016/.anireprosci.2010.03.012

[7] Rico Charlène, Drouilhet Laurence, Salvetti Pascal, DalbièsTran Rozenn, Jarrier Peggy, Touzé Jean-Luc, Pillet Elodie, Ponsart Claire, Fabre Stéphane MD. Determination of antiMüllerian hormone concentrations in blood as a tool to select Holstein donor cows for embryo production: from the laboratory to the farm. Reprod Fertil Dev 2012; 24: 932-44. https://doi.org/10.1071/RD11290

[8] Gasparrini B. In vitro embryo production in buffalo species: State of the art. Theriogenology 2002. https://doi.org/10.1016/S0093-691X(01)00669-0

[9] Neglia G, Gasparrini B, Caracciolo di Brienza V, Di Palo R, Campanile G, Antonio Presicce G, et al. Bovine and buffalo in vitro embryo production using oocytes derived from abattoir ovaries or collected by transvaginal follicle aspiration. Theriogenology 2003; 59: 1123-30.

https://doi.org/10.1016/S0093-691X(02)01170-6

[10] Gasparrini B, Sayoud H, Neglia G, De Matos DG, Donnay I, Zicarelli L. Glutathione synthesis during in vitro maturation of buffalo (Bubalus bubalis) oocytes: Effects of cysteamine on embryo development. Theriogenology 2003.

https://doi.org/10.1016/S0093-691X(03)00098-0

[11] Sá Filho MF, Carvalho NAT, Gimenes LU, Torres-Júnior JR, Nasser LFT, Tonhati $\mathrm{H}$, et al. Effect of recombinant bovine somatotropin (bST) on follicular population and on in vitro buffalo embryo production. Anim Reprod Sci 2009. https://doi.org/10.1016/j.anireprosci.2008.06.008

[12] Gimenes LU, Ferraz ML, Araujo A, Fantinato Neto $P$, Chiarati MR, Mesquita LG, et al. 273 Ovum pickup at different times of a synchronized follicular wave did not affect IVP in bos indicus, bos taurus, or bubalus bubalis. Reprod Fertil Dev 2010.

https://doi.org/10.1071/RDv22n1Ab273

[13] Felipe Gamarra P, Viviana Rendón V, Aldemar Chávez R, Leonardo Perez S, Cardona-Maya W, Jesús Berdugo G. Establishing an in vitro production program for buffalo embryos (Bubalus bubalis) in Colombia. Rev MVZ Cordoba 2015. https://doi.org/10.21897/rmvz.80
Pontes JHF, Melo Sterza FA, Basso AC, Ferreira CR, Sanches BV, Rubin KCP, et al. Ovum pick up, in vitro embryo production, and pregnancy rates from a large-scale commercial program using Nelore cattle (Bos indicus) donors. Theriogenology 2011; 75: 1640-6. https://doi.org/10.1016/j.theriogenology.2010.12.026

[15] Konrad J, Clérico G, Garrido MJ, Taminelli G, Yuponi M, Yuponi R, et al. Ovum pick-up interval in buffalo (Bubalus bubalis) managed under wetland conditions in Argentina: Effect on follicular population, oocyte recovery, and in vitro embryo development. Anim Reprod Sci 2017. https://doi.org/10.1016/j.anireprosci.2017.06.004

[16] Di Francesco S, Boccia L, Campanile G, Di Palo R, Vecchio $D$, Neglia G, et al. The effect of season on oocyte quality and developmental competence in Italian Mediterranean buffaloes (Bubalus bubalis). Anim Reprod Sci 2011. https://doi.org/10.1016/j.anireprosci.2010.11.009

[17] Neglia G, Gasparrini B, Vecchio D, Boccia L, Varricchio E, Di Palo $\mathrm{R}$, et al. Long term effect of Ovum Pick-up in buffalo species. Anim Reprod Sci 2011.

https://doi.org/10.1016/j.anireprosci.2011.01.011

[18] Benjamin G. Brackett GO. Capacitation of Rabbit Spermatozoa in vitro No Title. Biol Reprod 1975; 12: 260-74. https://doi.org/10.1095/biolreprod12.2.260

[19] Gimenes LU, Ferraz ML, Fantinato-Neto P, Chiaratti MR, Mesquita LG, Sá Filho MF, et al. The interval between the emergence of pharmacologically synchronized ovarian follicular waves and ovum pickup does not significantly affect in vitro embryo production in Bos indicus, Bos taurus, and Bubalus bubalis. Theriogenology 2015; 83: 385-93. https://doi.org/10.1016/j.theriogenology.2014.09.030

[20] Baldrighi J m, Sá Filho MF, Batista EOS, Lopes RNVR, Visintin JA, Baruselli PS, et al. Anti-Mullerian hormone concentration and antral ovarian follicle population in Murrah heifers compared to Holstein and Gyr kept under the same management. Reprod Domest Anim 2014; 49: 1015-20. https://doi.org/10.1111/rda.12430

[21] Viana JHM, Figueiredo ACS, Gonçalves RLR, Siqueira LGB. A historical perspective of embryo-related technologies in South America. Anim Reprod 2018. https://doi.org/10.21451/1984-3143-AR2018-0016

[22] La Marca A, Sighinolfi G, Radi D, Argento C, Baraldi E, Artenisio $\mathrm{AC}$, et al. Anti-Mullerian hormone (AMH) as a predictive marker in assisted reproductive technology (ART). Hum Reprod Update 2010; 16: 113-30. https://doi.org/10.1093/humupd/dmp036

[23] Hirayama H, Naito A, Fukuda S, Fujii T, Asada M, Inaba Y, et al. Long-term changes in plasma anti-Müllerian hormone concentration and the relationship with superovulatory response in Japanese Black cattle. J Reprod Dev 2017; 63 : 95-100. https://doi.org/10.1262/jrd.2016-019

[24] Ghanem N, Jin JI, Kim SS, Choi BH, Lee KL, Ha AN, et al. The Anti-Mullerian Hormone Profile is Linked with the In vitro Embryo Production Capacity and Embryo Viability after Transfer but Cannot Predict Pregnancy Outcome 2016; 310: 301-10.

https://doi.org/10.1111/rda.12681

[25] Durlinger A, Visser J TA. Regulation of ovarian function: the role of anti-Mullerian hormone. Reproduction 2002; 124: 6019.

https://doi.org/10.1530/rep.0.1240601

[26] Gimenes, L. U., Fantinato Neto, P., Arango, J. S. P., Ayres, $\mathrm{H}$., \& Baruselli PS. Follicular dynamics of Bos indicus, Bos taurus and Bubalus bubalis heifers treated with norgestomet ear implant associated or not to injectable progesterone. Anim Reprod Sci 2009; 6: 256.

[27] Alvarez P, Spicer LJ, Chase CC, Payton ME, Hamilton TD, Stewart RE, et al. Ovarian and endocrine characteristics 
during an estrous cycle in Angus, Brahman, and Senepol cows in a subtropical environment. J Anim Sci 2000. https://doi.org/10.2527/2000.7851291x

[28] Nuttinck F, Charpigny G, Mermillod P, Loosfelt H, Meduri G, Freret $S$, et al. Expression of components of the insulin-like growth factor system and gonadotropin receptors in bovine cumulus-oocyte complexes during oocyte maturation. Domest Anim Endocrinol 2004. https://doi.org/10.1016/j.domaniend.2004.03.003

[29] Ferraz ML, Sá Filho MF, Batista EOS, Watanabe YF, Watanabe MR, Dayan A, et al. Paradoxical effects of bovine somatotropin treatment on the ovarian follicular population and in vitro embryo production of lactating buffalo donors submitted to ovum pick-up. Anim Reprod Sci 2015. https://doi.org/10.1016/j.anireprosci.2014.12.017

[30] Baruselli PS, Batista EOS, Vieira LM, Ferreira RM, Guerreiro $B G$, Bayeux BM, et al. Factors that interfere with oocyte quality for in vitro production of cattle embryos: effects of different developmental \& reproductive stages. Anim Reprod 2016.

https://doi.org/10.21451/1984-3143-AR861

[31] Mondadori RG, Luque MCA, Santin TR, Báo SN. Ultrastructural and morphometric characterization of buffalo (Bubalus bubalis) ovarian preantral follicles. Anim Reprod Sci 2007; 97: 323-33.

https://doi.org/10.1016/j.anireprosci.2006.02.010

[32] Baruselli PS, Soares JG, Bayeux BM, Silva JCB, Mingoti RD, Carvalho NAT. Assisted reproductive technologies (ART) in water buffaloes. Anim Reprod 2018; 15: 971-83. https://doi.org/10.21451/1984-3143-AR2018-0043

[33] Anwar M, Ullah N. Early development and location of embryos in the reproductive tract of Nili Ravi buffalo (Bubalus bubalis): A retrospective analysis. Theriogenology 1998. https://doi.org/10.1016/S0093-691X(98)00066-1

[34] Galli C, Crotti G, Notari C, Turini P, Duchi R, Lazzari G. Embryo production by ovum pick up from live donors. Theriogenology 2001.

https://doi.org/10.1016/S0093-691X(01)00486-1

[35] Pawshe CH, Appa Rao KBC, Totey SM. Effect of insulin-like growth factor I and its interaction with gonadotropins on in vitro maturation and embryonic development, cell proliferation, and biosynthetic activity of cumulus-oocyte complexes and granulosa cells in buffalo. Mol Reprod Dev 1998.

https://doi.org/10.1002/(SICl)1098-

2795(199803)49:3<277::AID-MRD8>3.0.CO;2-L

[36] Kumar, P., A. Verma, B. Roy, S. Rajput, S. Ojha, S. Anand, P., Yadav, J. Arora S, De SIG, and TKD. Effect of varying glucose concentrations during in vitro maturation and embryo culture on efficiency of in vitro embryo production in buffalo. Reprod Domest Anim 2012; 47: 269-73. https://doi.org/10.1111/j.1439-0531.2011.01849.x
Nandi S, Ravindranatha BM, Gupta PSP, Raghu HM, Sarma $P$ V. Developmental competence and post-thaw survivability of buffalo embryos produced in vitro: Effect of growth factors in oocyte maturation medium and of embryo culture system. Theriogenology 2003. https://doi.org/10.1016/S0093-691X(03)00148-1

[38] Eswari S, Sai Kumar G, Sharma GT. Expression of mRNA encoding leukaemia inhibitory factor (LIF) and its receptor (LIFR??) in buffalo preimplantation embryos produced in vitro: Markers of successful embryo implantation. Zygote 2013. https://doi.org/10.1017/S0967199412000172

[39] Boccia L, Rubessa M, De Blasi M, Di Francesco S, Albero G Neglia G, and Gasparrini B. Hyaluronic Acid improves cryotolerance of buffalo (bubalus bubalis) in vitro-derived embryos. Reprod Fert Devel 2011; 24: 138. https://doi.org/10.1071/RDv24n1Ab52

[40] Boccia L, De Blasi M, Zullo G, Longobardi V, Vecchio D, and Gasparrini B. L-carnitine during in vitro culture enhances the cryotolerance of buffalo (bubalus). Reprod Fertil Dev 2012; 25: 214. https://doi.org/10.1071/RDv25n1Ab133

[41] Blondin $P$, Bousquet $D$, Twagiramungu $H$, Barnes $F$, Sirard M-A. Manipulation of follicular development to produce developmentally competent bovine oocytes. Biol Reprod 2002.

https://doi.org/10.1095/biolreprod66.1.38

[42] Nivet AL, Bunel A, Labrecque R, Belanger J, Vigneault C, Blondin $\mathrm{P}$, et al. FSH withdrawal improves developmental competence of oocytes in the bovine model. Reproduction 2012.

https://doi.org/10.1530/REP-11-0391

[43] Konrad JL, Berdugo JA, Yuponi R, Vallejos N, Ledesma M, Crudeli G, Sansinena M. Effect of a one-time, strategic donor $\mathrm{FSH}$-treatment on oocyte and embryo production in a commercial buffalo IVP program. Anim Reprod 2018; 15: 1129.

[44] Soares F, Carvalho NAT, Basso AC, Watanabe Y, Watanabe $Y$, Bayeux BM, Mingoti RD. Baruselli P. Superstimulation prior to ovum pick-up to improve in vitro embryo production in buffalo donors. Anim Reprod 2018; 15: 1153.

[45] Campanile G, Neglia G, Gasparrini B, Galiero G, Prandi A, Di Palo R, et al. Embryonic mortality in buffaloes synchronized and mated by $\mathrm{Al}$ during the seasonal decline in reproductive function. Theriogenology 2005; 63: 2334-40. https://doi.org/10.1016/j.theriogenology.2004.10.012

[46] Campanile G, Neglia G, D'Occhio MJ. Embryonic and fetal mortality in river buffalo (Bubalus bubalis). Theriogenology 2016. https://doi.org/10.1016/j.theriogenology.2016.04.033

\section{DOI: https://doi.org/10.6000/1927-520X.2020.09.05}

\section{(c) 2020 Berdugo et al.; Licensee Lifescience Global.}

This is an open access article licensed under the terms of the Creative Commons Attribution Non-Commercial License (http://creativecommons.org/licenses/by-nc/3.0/) which permits unrestricted, non-commercial use, distribution and reproduction in any medium, provided the work is properly cited. 